\title{
Biotelemetry system for Epilepsy Seizure Control
}

Federal Manufacturing \& Technologies

LaCurtise Smith

George W. Bohnert

\section{KCP-613-8588}

Published June 2009

\section{Final Report}

Approved for public release; distribution is unlimited.

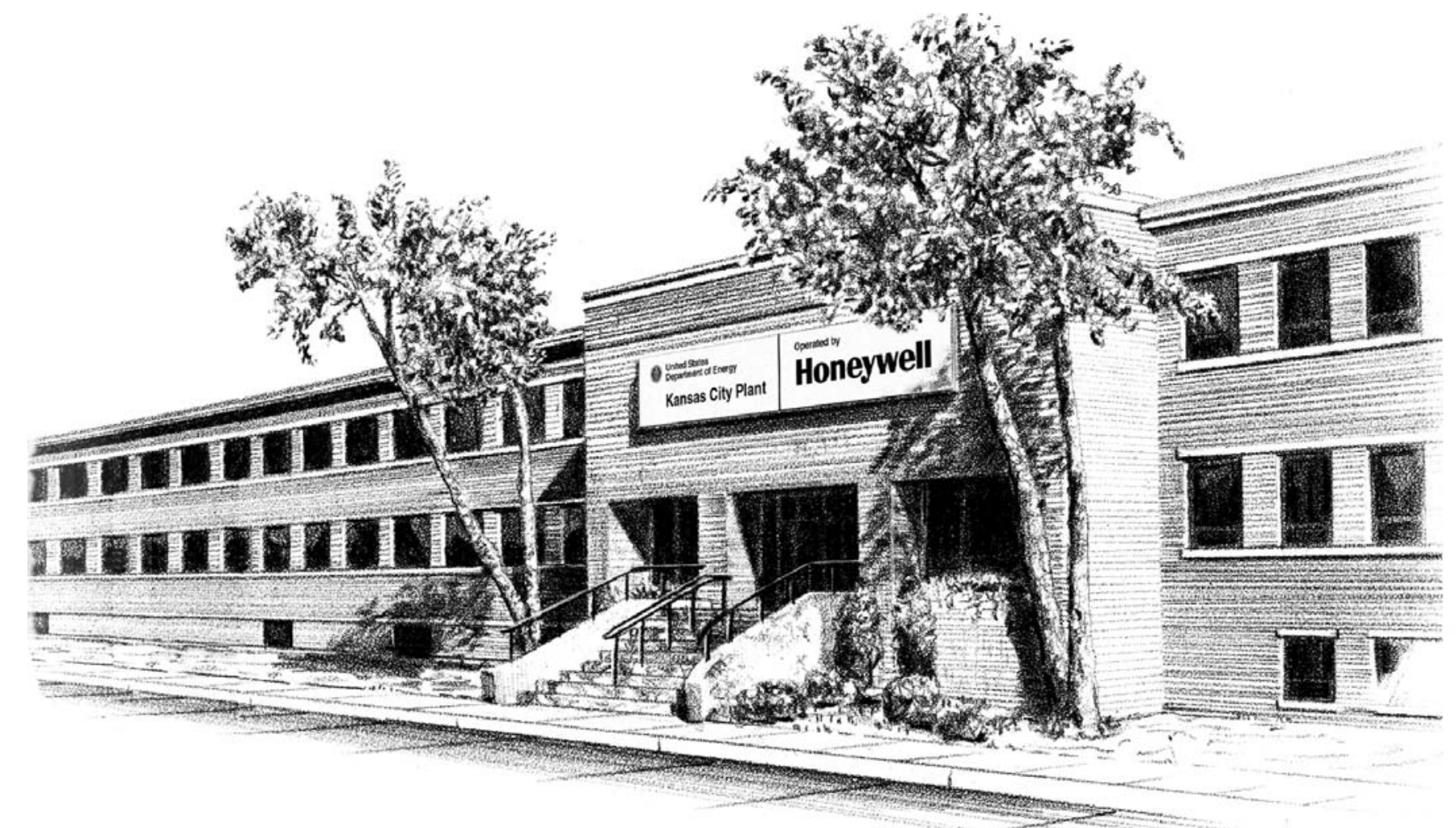

Prepared under prime contract DE-ACO4-01AL66850 for the 


\section{DISCLAIMER}

This report was prepared as an account of work sponsored by an agency of the United States Government. Neither the United States Government nor any agency thereof, nor any of their employees, makes any warranty, express or implied, or assumes any legal liability or responsibility for the accuracy, completeness, or usefulness of any information, apparatus, product, or process disclosed, or represents that its use would not infringe privately owned rights. Reference herein to any specific commercial product, process or service by trade names, trademark, manufacturer, or otherwise, does not necessarily constitute or imply its endorsement, recommendation or favoring by the United States Government or any agency thereof. The views and opinions of authors expressed herein do not necessarily state or reflect those of the United States Government or any agency thereof.

All data prepared, analyzed and presented has been developed in a specific context of work and was prepared for internal evaluation and use pursuant to that work authorized under the reference contract. Reference herein to any specific commercial product, process or service by trade name, trademark, manufacturer, or otherwise, does not necessarily constitute or imply its endorsement, recommendation or favoring by the United States Government, any agency thereof or Honeywell Federal Manufacturing \& Technologies, LLC.

Printed in the United States of America.

This report has been reproduced from the best available copy.

Available to DOE and DOE contractors from the Office of Scientific and Technical Information, P.O. Box 62, Oak Ridge, Tennessee 37831; prices available from (865) 576-8401, FTS 626-8401.

Available to the public from the National Technical Information Service, U.S. Department of Commerce, 5285 Port Royal, Rd., Springfield, Virginia 22161, (703) 487-4650.

A prime contractor with the United States Department of Energy under Contract Number DE-AC04-O1AL66850
Honeywell Federal Manufacturing \& Technologies

P.O. Box 419159

Kansas City, Missouri, 64141-6159 


\section{Honeywell}

KCP-613-8588

Distribution Category UC-47

Approved for public release; distribution is unlimited.

\section{BIOTELEMENTRY SYSTEM FOR EPILEPSY SEIZURE CONTROL}

LaCurtise Smith

George W. Bohnert

Published June 2009

Final Report 



\section{Contents}

Section

Page

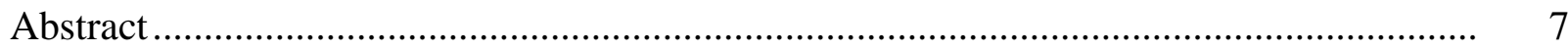

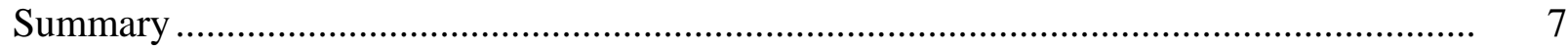

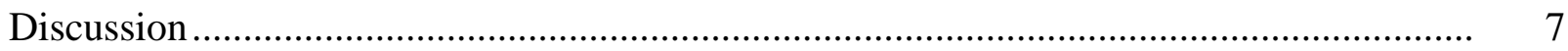

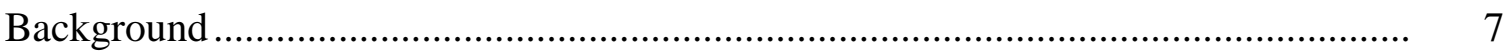

Developing Alternative Therapies for Epilepsy …...................................... 7

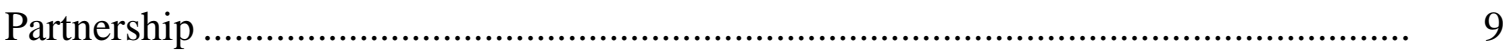

Argonne National Laboratory ............................................................... 9

The Kansas City Plant........................................................................... 9

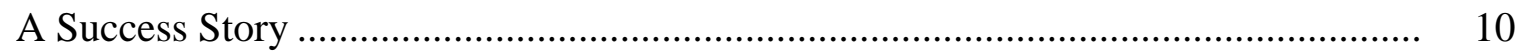

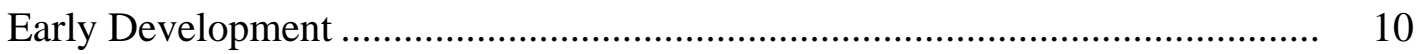

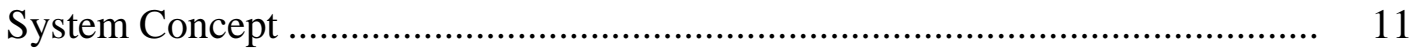

Long Term Benefits ......................................................................... 12

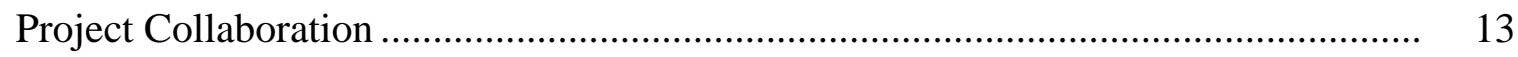

Expected Economic/Industry Impact ........................................................... 14

Benefits to DOE .......................................................................................

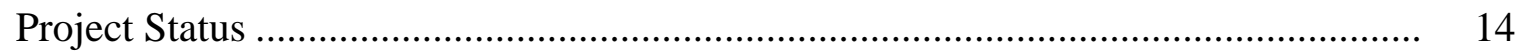

Points of Contact for Project Information........................................................ 15

Technical Commercialization ...................................................................... 15

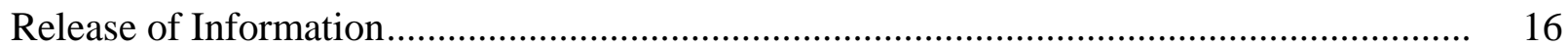

Appendix

Biotelemetry System for Epilepsy Seizure Control Project Team ............................ 17 


\section{Illustrations}

Figure Page

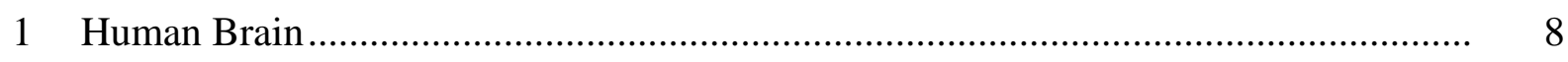

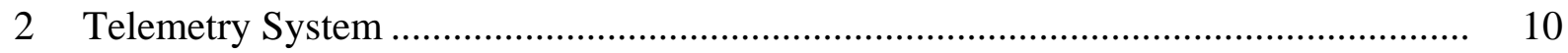

3 Cooling Device Prototype......................................................................... 11

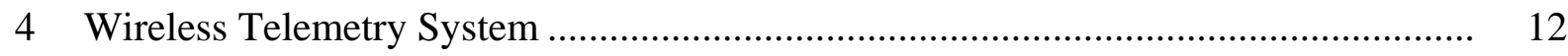

$5 \quad$ Telemetry Device Prototype ......................................................................... 12 


\begin{abstract}
The Biotelemetry System for Epilepsy Seizure Control Project developed and tested an automated telemetry system for use in an epileptic seizure prevention device that precisely controls localized brain temperature. This project was a result of a Department of Energy (DOE) Global Initiatives for Proliferation Prevention (GIPP) grant to the Kansas City Plant (KCP), Argonne National Laboratory (ANL), and Pacific Northwest National Laboratory (PNNL) to partner with Flint Hills Scientific, LLC, Lawrence, KS and Biophysical Laboratory Ltd (BIOFIL), Sarov, Russia to develop a method to help control epileptic seizures.
\end{abstract}

\title{
Summary
}

The focus of this project was to develop and test an automated telemetry system suitable for use in an epileptic seizure prevention device that precisely controls localized brain temperature. The telemetry device incorporates an integrated RF transceiver and microprocessor. The unit operates at low power levels and is capable of receiving, sending, and processing signals. This project draws on the combined technology base and expertise of the institutions working together through the GIPP grant.

GIPP research projects are selected for their commercial potential and are designed to lead to peaceful, long-term employment and income for former Soviet Union weapons workers. The program benefits from the Russians' expertise in conducting research and development at a fraction of the cost. Operating on a conservative budget, the American tax dollars that fund GIPP programs, such as the epilepsy prevention research, generate tremendous yields.

The epilepsy seizure control system works by regulating the brain's temperature, thereby preventing the epileptic seizure from developing. Brain temperature and activity is monitored via a probe implanted in the patient's brain. When warning signs are received a cooling system is activated prior to the occurrence of seizure manifestations.

This report provides the accomplishments and current status of the seizure control system, information about the project team, and the benefits provided through the research and development of the device to control epileptic seizures.

\section{Discussion}

\section{Background}

\section{Developing Alternative Therapies for Epilepsy}

Epilepsy has been recognized as a unique disorder for thousands of years, with references to its symptoms occurring throughout the ages-from Babylonian tablets to the Bible. Julius Caesar was perhaps its best-known victim. Derived from the Greek word "epilambabein," meaning to seize or attack, epilepsy is a neurological condition that makes people susceptible to changes in sensation, awareness, or behavior due to brief electrical disturbances of the brain. 
These disturbances, known as seizures, vary from a few moments of sensory disruption, to periods of unconsciousness or staring spells, to convulsions. Regardless of how the seizure manifests itself, the result is the same-disruption to the sufferer's life.

Approximately one percent of the population of industrialized countries has epilepsy, with an even higher proportion in non-industrialized countries. Many of these people (20 to 40 percent in industrialized countries) do not respond to existing medication or treatments, and must suffer through the constant threat of seizures. Medications, although very useful, don't work for a good number of patients. These patients have at least one seizure a month-enough to severely disrupt their lives. Epilepsy interferes with both the patient's work life and personal life, and often leads to isolation and depression. Many people suffering from epileptic seizures are highly educated, creative, and capable of productively serving their families and humanity. However the illness puts restrictions on their work options and way of life and they are constantly threatened by mortal danger.

The aim of the epilepsy control project is to provide opportunities for these people to experience a normal life without destructive chemical therapeutic remedies. Currently, 2.7 million people in the United States suffer from epilepsy. Furthermore, a poll commissioned in 1992 which interviewed over 1,000 epilepsy sufferers discovered that only 15 percent of respondents said they were doing well, meaning they had no seizures and no side effects from their drugs. Clearly, there is a great need for other therapeutic measures to relieve the pain and stress of epilepsy.

In 2001, the DOE GIPP program granted a \$1.5 million to KCP, ANL, and PNNL to partner with Flint Hills Scientific, LLC, a small high-tech research and development biotech company based in Lawrence, KS and Biophysical Laboratory Ltd (BIOFIL), a small, private science company in Sarov, Russia to develop a method to help control seizures.

The project focused on controlling epileptic seizures by regulating the brain's temperature rather than other therapeutic alternatives such as electric brain stimulation which contains the risk of making seizures worse. An obstacle to this approach is that the human brain contains large amounts of fat, which is a very good insulator, therefore, making thermal energy transfer challenging (see Figure 1). Any device that would control epilepsy by regulating the brain's temperature would have to work extremely quickly in order to counteract rising temperatures.

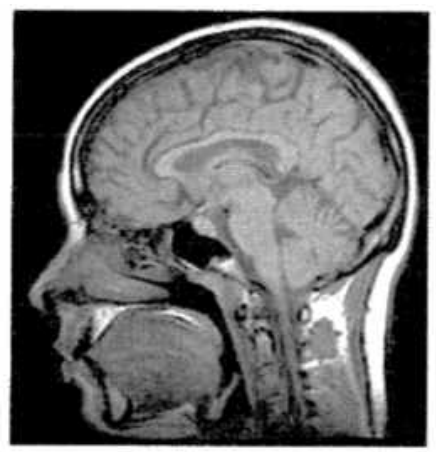

Figure 1. Human Brain 
Working with the Russian scientists, Flint Hills Scientific has developed probes that quickly cool the brain, opening up avenues for thermal therapy. The Russian and American scientists, closely integrated as one team, worked to refine the geometry and size of the probes to minimize the time necessary to reduce the brain's temperature, thus helping to fight off epileptic seizures. Now that the probes are completed the project is at the midway point and Flint Hills Scientific can work on commercializing its treatment. The thermal probes may have other applications as well. Potentially, they can be used for the treatment of movement and psychological disorders, and chronic pain relief.

The two national labs (ANL, PNNL) along with the KCP and Flint Hills Scientific have collaborated on the epilepsy control project. The portable system includes three main parts: 1) an implantable sensor system measuring local temperature and electrical activity of the brain, which may be used to detect or predict an epileptic seizure; 2) an integrated brain tissue cooling probe (stimulating unit); and 3) a telemetry system supplying information exchange between the sensor and stimulating unit.

\section{Partnership}

\section{Argonne National Laboratory}

This lab is responsible for the design and integration of both the coolant system and the implantable probe. PNNL originally had the mission to develop the self-contained coolant system but transferred that responsibility to ANL. The coolant system is still being developed but the implantable probes have been bench-top tested for effectiveness. The probe is composed of two parts: 1) a sensor to determine local brain tissue temperature; and 2) a manifold and tubing for cooling a localized brain tissue site.

Flint Hills Scientific, with the help of former weapons scientists from BIOFIL in Sarov, Russia, has been working diligently to develop alternative treatments. Partners across the government, medical, and private industry are working together to write a new page in the history of epilepsy. Under the framework of the GIPP program, BIOFIL would be engaged in the research, design, and analysis of high-tech medical components for the personal, automatic, radiotelemetric device. BIOFIL, Russia was created in 1991 by the Russian Federal Nuclear Center (VNIIEF) and the Science and Technology Center of Eye Microsurgery for biomedical studies and state-ofthe-art technology and medical device development. BIOFIL has experience in the excitation and propagation of hypersonic waves in eye tissue collagen and in control telemetry systems that were used in the epilepsy control project framework. BIOFIL personnel consist of highly competent scientists (theorists and experimenters), mathematicians, programmers, designers, engineers, and technicians earlier engaged in defense development in RFNC-VNIIEF, Sarov. BIOFIL has wide experience in collaboration with American scientists and has already successfully accomplished the tasks of creating a device for pain relief by transcutaneous electrical nerve stimulation and a miniature telemetry device.

\section{The Kansas City Plant}

A main element of the epileptic control device was developed at KCP. This miniature automated control telemetry system provides communication and data processing between the sensor and control device (see Figure 2). KCP provided expertise in hardware selection and modification of 
the telemetry component of the device. Field testing for proof of principle was conducted. The experience and expertise of KCP engineers facilitated design and miniaturization of the device.

KCP administers the U.S. Department of Energy’s GIPP program. As the federal partner in this project, KCP acts as: 1) project facilitator, 2) funding provider, and 3) technical partner.

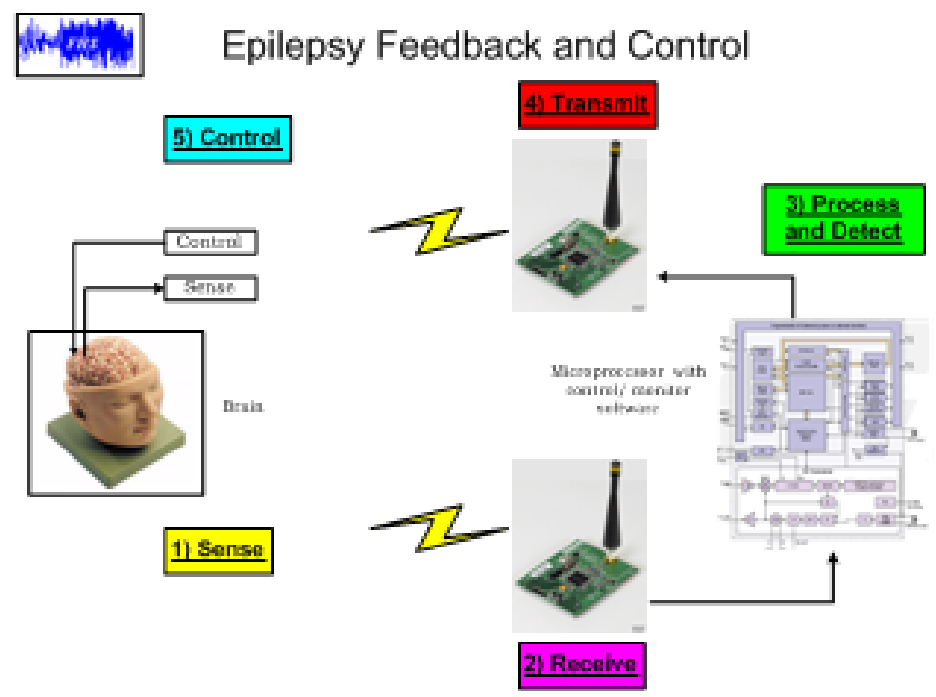

Figure 2. Telemetry System

\section{A Success Story}

\section{Early Development}

Flint Hills first contacted the Kansas City Plant for help with implementing into a portable device an algorithm they had developed for real-time detection, warning, and quantification of seizures. KCP engineers worked with Flint Hills' Dr. Osorio and Dr. Frei to develop the first electronic, portable device to detect and warn of impending seizures. This first prototype was developed at the Kansas City Plant in the late 1990s. The initial contact laid the foundation for what would later become a GIPP partnership.

Having developed a critical first detection/warning prototype, the team started looking at implantable devices to warn about an impending seizure and trigger an automatic therapy. The automatic therapy that the device triggers could be electrical, cooling of a brain region, or even local delivery of a drug. Currently, Drs. Osorio, Frei, and the rest of the GIPP epilepsy prevention team are working on the cooling strategy. 


\section{System Concept}

As stated previously, the epilepsy control system works by tracking the brain temperature via an implanted probe. When the probe detects a change in brain patterns, the changes are sent wirelessly to a telemetry device, which activates a cooling system prior to the occurrence of clinical/behavioral manifestations of the seizure. Coolant is delivered to the implanted probe inserted in the brain via a connecting tube.

The team of three Americans and fifteen Russians has made incredible strides in developing this cooling technology. The success of this project led Flint Hills Scientific to apply for another Initiatives for Proliferation Prevention grant for the development of low-risk electrical implants to treat epilepsy. This second application was also driven by the excellent working relationship between the Americans and the Russian scientists, who were described by Dr. Osorio as "very cordial, very thoughtful, and exceptionally competent.” While the Americans and Russians had different scientific styles, a good rapport developed quickly, and the project evolved into a "highly integrated process. The end result of the collaboration, despite the contrasting styles, has shown the partnership was extremely valuable” (see Appendix).

This portable early warning system as described above contains three main parts: 1) an implantable sensor (that measures local temperature of the brain area and nearby electrical signals, either or both of which may be used to detect an epileptic seizure); 2) a brain tissue cooling device (that initiates cessation of the seizure); and 3) a telemetry system (that enables information exchange between the sensor and cooling device and includes digital signal processing).

The implantable temperature sensor has already been developed by BIOFIL with Argonne engineers under the leadership of Sami Gopalsami and Paul Raptis. The passive sensor can measure changes in brain temperate of $1 / 1000^{\circ} \mathrm{C}$. A prototype cooling probe has been developed by BIOFIL and Argonne (see Figure 3); however, further reduction in size is needed to reduce brain tissue injury during implanting the probe.

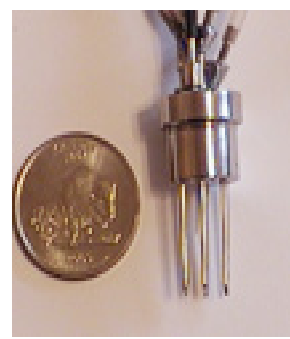

Prototype cooling device, including seven needle-shaped cooling probes and temperature sensor, optirnized to cool brain tissue in order to stop seizures.

Figure 3. Cooling Device Prototype 
KCP's main mission was the miniaturization of the telemetry system and the integration of all epilepsy prevention system components. Using its expertise in miniaturization, the Kansas City Plant has greatly improved its original prototype of the wireless telemetry system, reducing it to approximately the size of a pager (see Figures 4 and 5).

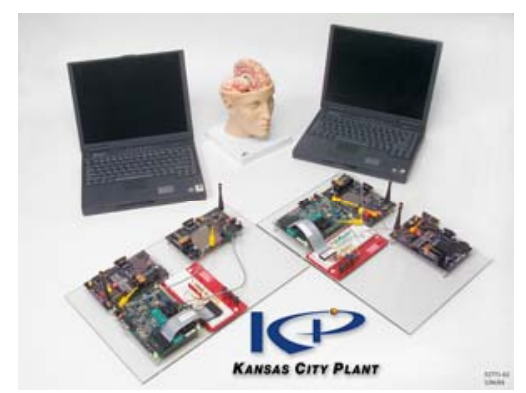

Figure 4. Wireless Telemetry System

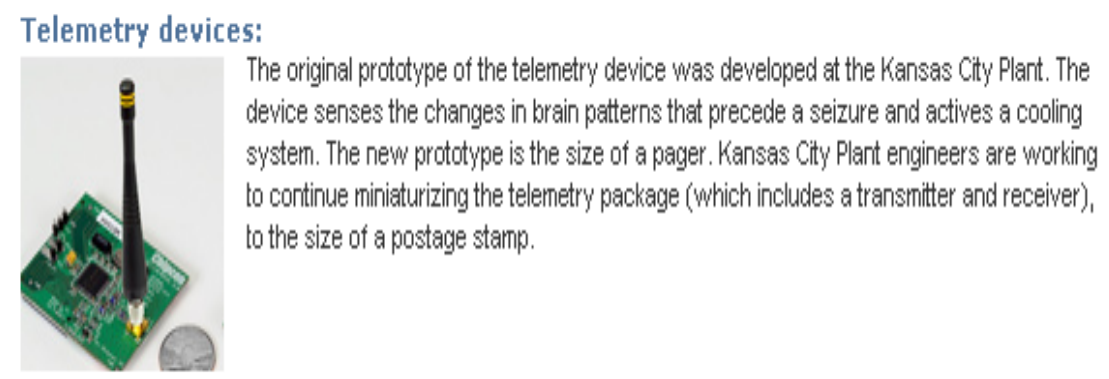

Figure 5. Telemetry Device Prototype

The smaller the device, the less obtrusive it is for the patient. While currently an external device, if small enough, it could be implanted in the patient. The telemetry system is microprocessor controlled. Integration of the coolant system, probe, and telemetry unit is ongoing. The GIPP team expects to have a complete prototype to test within the next five years.

\section{$\underline{\text { Long Term Benefits }}$}

Traditional treatment for epilepsy consists primarily of seizure-preventing medications. If drugs are not effective, brain surgery is the alternative. In patients where the seizures are localized, the part of the brain causing the seizures is located and cut out. Unfortunately, brain surgery is very expensive and very limited. Only about 2,000 to 3,000 epilepsy patients undergo this surgery in the United States each year while approximately 600,000 may benefit from this approach.

Estimated annual cost of epilepsy care in the U.S. runs well over 12 billion dollars. Through the GIPP program, the new epilepsy prevention system plans to make treatment affordable.

"I’ve worked in epilepsy for many years," Osorio said. "I handle the cases that don't respond to, or aren't fully controlled by medication, which are about 20 to 40 percent of all cases. These patients have at least one seizure a month — enough to severely disrupt their lives.” Epilepsy interferes with both the patient's work and personal life, and often leads to isolation and depression. Currently, 2.7 million people in the United States suffer from epilepsy. 
“It became very clear to me that medications, although very useful, don't work for a good number of patients. So I decided to look at other ways of dealing with this," Osorio said. Since a large number of patients suffer from seizures that are concentrated in one spot in the brain, Osorio and Frei decided to look at local, direct brain intervention.

\section{Project Collaboration}

The epilepsy seizure control project draws on the combined technology base and expertise of the four institutions listed below.

Flint Hill Scientific LLC, USA is a medical device development stage company under the direction of Dr. Mark Frei and Dr. Ivan Osorio. Dr. Osorio is also a professor of neurology and specializes in epilepsy research at the Comprehensive Epilepsy Center at Kansas University. Within the project framework, this institution and Dr. Osorio will provide the scientific leadership and organize the work of other institutions related to this device.

Argonne National Laboratory has a mission to apply a unique mix of world-class science, engineering, and user facilities to deliver innovative research and technologies. Dr. Osorio was quick to emphasize the important role played in the project by the Argonne staff, stating, "The program never would have started without the diligent work of the staff at Argonne National Laboratory. As the interlocutor between Flint Hills and BIOFIL, Argonne laid the groundwork for the tremendous accomplishments that have followed.”

Kansas City Plant, USA has experience in telemetry systems and miniature product development. KCP is one of the nation's most diverse low-volume, high-reliability production facilities. KCP provides high-tech production services to government agencies such as the National Nuclear Security Administration with high-quality requirements.

BIOFIL (Biophysical Laboratory), Russia was created in 1991 by the Russian Federal Nuclear Center (VNIIEF) and the Science and Technology Center of Eye Microsurgery for biomedical studies and up-to-date technologies and medical devices development. BIOFIL has experience in the excitation and propagation of hypersonic waves in eye tissue collagen and control telemetry systems that were used in the project framework. BIOFIL personnel consist of high quality scientists (theorists and experimenters), mathematicians, programmers, designers, engineers, and technicians earlier engaged in defense development in RFNC-VNIIEF, Sarov. BIOFIL has wide experience in collaboration with American scientists and has already successfully accomplished the tasks of creating a device for pain relief by transcutaneous electrical nerve stimulation and a miniature telemetry device.

This project was pivotal in the development of BIOFIL Ltd. It provided crucial funding for staff, computers equipment, training and technology advancement for the emerging company. Nineteen former weapons of mass destruction (WMD) technical personnel (engineers, scientists, designers, and technologists), many of whom had experience in the design, production, and testing of WMD, were able to be employed in peaceful endeavors. In the course of the project, BIOFIL Ltd received experience in the fast-paced development of medical devices. This expertise also will give BIOFIL a chance to become an attractive partner on the world market. 
Wide international collaboration between Russian and U.S. scientists took place in the joint scientific research under the umbrella of this project.

\section{Expected Economic / Industry Impact}

The final goal of the project was the creation of devices preventing epileptic seizures. Medical equipment for the treatment of epilepsy is a medical industry area focus. A world leader in medical equipment production, Medtronic, already has shown interest in the commercialization of the planned device. The annual market size estimate for a successful product of this type is approximately one billion dollars.

\section{Benefits to DOE}

This project redirected 19 full-time scientists that were formerly engaged in the production of nuclear weapons. As a result of this project and the funding provided by DOE's nonproliferation program, these former weapons scientists were employed and fully engaged by BIOFIL Ltd. A long-term mutually beneficial business relationship has been formed and is likely to continue long after this project is complete. The goal of this nonproliferation program is to create longterm sustainable business relationships by redirecting former WMD scientist into commercial endeavors. The seizure prevention project accomplished this goal.

\section{Project Status}

The prototype telemetry system is completed and KCP has developed custom code for it. Testing and integration of the tissue cooling system, the probe, and the telemetry system is ongoing. The GIPP team expects to have a complete prototype to test within the next five years..

The main goal of the GIPP project was to redirect the technical talents of former RFNC-VNIIEF weapons scientists and engineers into commercial applications. BIOFIL Ltd has grown to over 20 employees and expects to continue drawing additional former weapons scientist and engineers. In the course of project implementation, BIOFIL has received experience in the fastpaced industry of medical device creation. This experience also will give BIOFIL a chance to become an attractive partner on the world market. The Kansas City Plant is very proud to be a part of this growth and to provide an opportunity for this collaboration and friendship. 


\section{Points of Contact for Project Information}

Diana Ritter

U.S. Department of Energy

Kansas City Site Office

PO Box 410202

Kansas City, Mo 64141-0202

Tel: (816) 997-3914

Fax: (816) 997-5059

George Bohnert

The Kansas City Plant

PO Box 419159

Kansas City, MO 64141-6159

Tel: (816) 997-2612

Fax: (816) 997-2049
LaCurtise Smith

The Kansas City Plant

PO Box 419159

Kansas City, Mo 64141-6159

Tel. (816) 997-2857

Fax: (816) 997-2049

Ivan Osorio, M.D.

Mark G. Frei, Ph.D.

Flint Hills Scientific, L.L.C.

5040 Bob Billings Pkwy, Ste. A

Lawrence, KS 66049

\section{Technology Commercialization}

Flint Hill Scientific LLC expects to have a complete prototype to test within the next five years. 


\section{Release of Information}

I have reviewed the attached Project Accomplishment Summary (PAS) prepared by KCP and agree that the information about our CRADA may be released for external distribution.

Name: George Bohnert

Organization: The Kansas City Plant

Title: Staff Engineer

Name: LaCurtise Smith

Organization: The Kansas City Plant

Title: Project Manager

Date: May 07, 2009 


\section{Appendix}

The Biotelemetry System for Epilepsy Seizure Control Project Team

The project is a relationship between the following parties:

The Kansas City Plant

2000 E 95th Street

PO Box 419159

Kansas City, MO 64141-6159

\section{BIOPHYSICAL LABORATORY}

Prospekt Mira, 37.

Sarov Russia 607190

Flint Hills Scientific

Dr. Ivan Osorio

Dr. Mark Frei

Flint Hills Scientific, LLC

5040 Bob Billings Pkwy, Ste. A

Lawrence, Kansas 66049

The photo below is from a meeting held at Kansas University Medical Center to discuss new epilepsy treatment options.

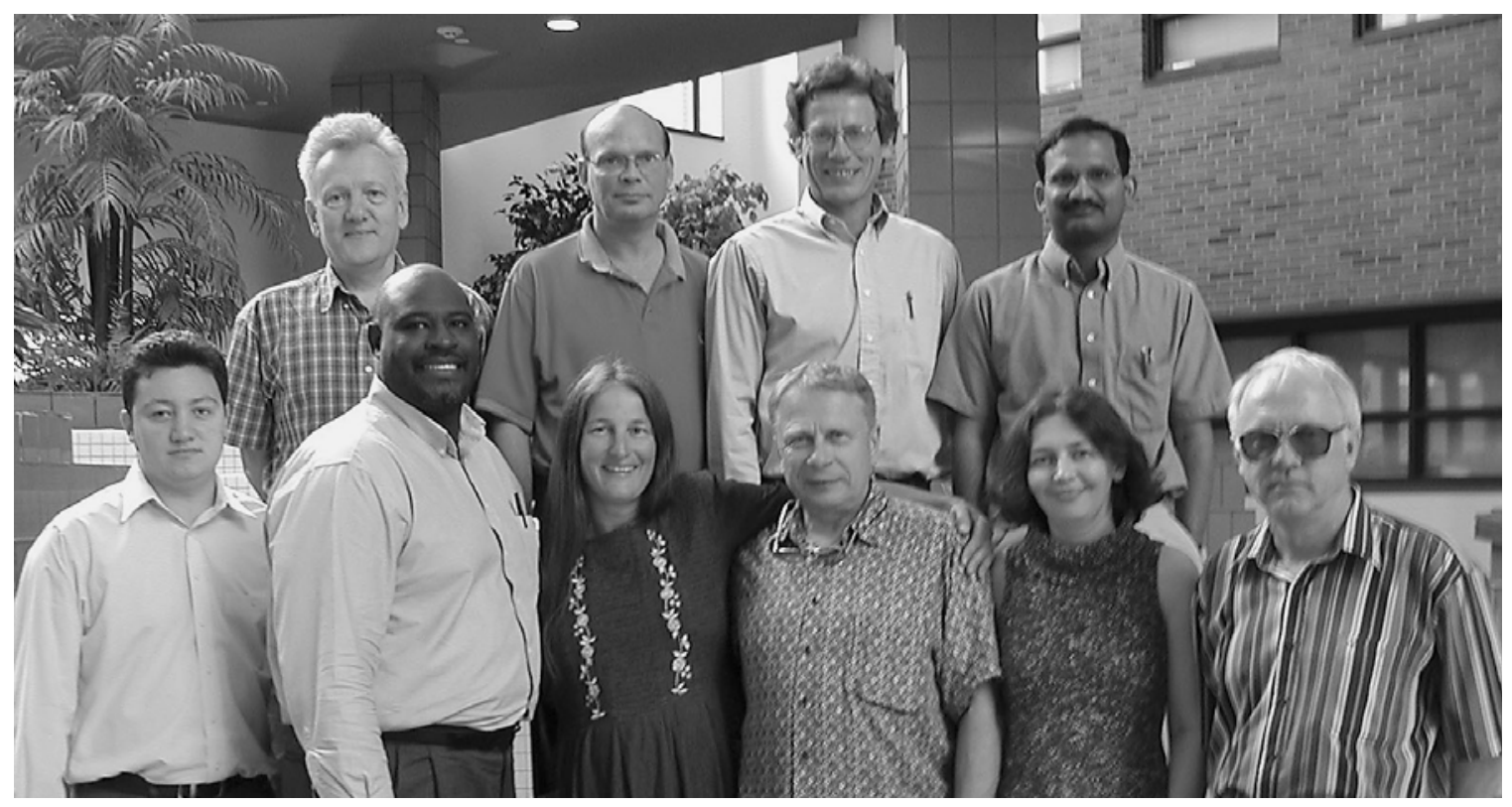

Front row from left: Eugene Kheyfets, LaCurtise Smith, Michele Friedrich, Stanislav Kulikov, Tatiana Lyubynskaya,Victor Eroshenko

Back row: Gennady Kochemasov, Paul Quirk, George Bohnert, Naresh Bhavaraju Team members not pictured: Paul Raptis, Sami Gopalsami, Dean Oliver, Walter Reevy, Steve Sedlock, Ivan Osorio 